\title{
Identificeerbaarheid van kinderen met een gehoorbeperking
}

\section{Een vergelijkende benadering}

\author{
Nathalie Boonen, Hanne Kloots en Steven Gillis \\ Universiteit Antwerpen
}

Studies on the speech and language development of hearing-impaired children often focus on (deviations in) the children's speech production. However, it is unclear if listeners also perceive differences between the speech of normally hearing and hearing-impaired children. This contribution wants to fill this void by investigating the overall perceived speech quality of both groups. Three groups of listeners (speech and language pathologists, primary school teachers and inexperienced listeners) judged 126 utterances of seven normally hearing children, seven children with an acoustic hearing aid and seven children with a cochlear implant, in a comparative judgment task. All children were approximately seven years old and received, in the case of the hearing-impaired children, their assistive hearing device before the age of two.

The online tool D-PAC was used to administer the comparative judgement task. The listeners compared stimuli in pairs and decided which stimulus sounded best. This method ultimately leads to a ranking in which all stimuli are represented according to their overall perceived speech quality.

The main result is that the speech of normally hearing children was preferred by the listeners. This indicates that, even after several years of device use, the speech quality of hearing-impaired children is perceived as different from that of normally hearing children. Within the group of hearingimpaired children, cochlear implanted children were judged to exhibit higher speech quality than acoustically hearing aided children, especially after a longer device use. The speech quality of the latter group, on the other hand, remained practically stable. Listeners, irrespectively of their degree of experience with (hearing-impaired) children's speech, completed the task similarly. In other words: the difference between the overall perceived speech quality of normally hearing and hearing-impaired children is salient for all listener groups and they all slightly preferred children with a cochlear implant over children with an acoustic hearing aid. 
Kernwoorden: taalverwerving, spraakperceptie, cochleair implantaat, akoestisch hoorapparaat, comparatieve beoordeling

\section{Inleiding}

In deze bijdrage onderzoeken we de herkenbaarheid van kinderen met een gehoorbeperking (Focus 1) bij drie groepen van luisteraars (Focus 2) met behulp van D-PAC, een tool voor comparatieve beoordeling (Focus 3).

\section{Focus 1: Wel/geen gehoorbeperking}

Ongeveer een op de duizend kinderen wordt geboren met een permanente gehoorbeperking (Kral \& O’Donoghue, 2010). Dankzij neonatale screening worden gehooraandoeningen tegenwoordig snel opgespoord en kan er zo spoedig mogelijk geremedieerd worden. Afhankelijk van de plaats en de ernst van de gehoorbeperking krijgen kinderen een akoestisch hoorapparaat of een cochleair implantaat (CI). Deze toestellen leveren geen perfect gehoor op, maar zorgen er wel voor dat de taal- en spraakontwikkeling van de betrokken kinderen veel vlotter verloopt dan vroeger voor mogelijk werd gehouden (Nicholas \& Geers, 2007).

Dankzij hoorhulpmiddelen verloopt de spraakontwikkeling van kinderen met een gehoorbeperking een stuk vlotter, maar toch is hun spraakproductie ${ }^{1}$ uiteindelijk niet helemaal identiek aan die van hun normaalhorende leeftijdsgenoten. Zo hebben kinderen met een gehoorbeperking doorgaans een kleinere klinkerruimte. Of anders geformuleerd: ze spreken hun vocalen centraler uit. Bij kinderen met een $\mathrm{CI}$ is deze tendens nog iets sterker dan bij kinderen met een akoestisch hoorapparaat (Verhoeven, Hide, De Maeyer, Gillis, \& Gillis, 2016). De orale klanken van kinderen met een gehoorbeperking klinken doorgaans ook wat nasaler dan die van normaalhorende kinderen. Bij kinderen met een akoestisch hoorapparaat en een gehoorverlies groter dan 70 decibel (dBHL) is deze tendens nog duidelijker dan bij kinderen met een CI (Baudonck, Van Lierde, D'Haeseleer, \& Dhooge, 2015). Verder is bijvoorbeeld ook al gebleken dat kinderen met een cochleair implantaat gemiddeld wat trager praten dan hun normaalhorende leeftijdsgenoten (Vanormelingen, De Maeyer, \& Gillis, 2016).

1. Onder "spraakproductie" wordt verstaan: "In phonetics and psycholinguistics, a term for the activity of the respiratory, phonatory and articulatory systems during speech, along with the associated neural programming required for their co-ordination and use. A contrast is usually drawn with the receptive aspects of spoken communication, such as speech perception and recognition." (Crystal, 2003, p. 428). 
Al bij al zijn de akoestische verschillen tussen de spraak van kinderen met een gehoorbeperking en die van hun normaalhorende leeftijdsgenoten echter vrij subtiel. We kunnen ons dan ook afvragen in hoeverre deze verschillen een luisteraar opvallen. Dat wordt onze eerste onderzoeksvraag: in hoeverre kunnen luisteraars normaalhorende kinderen en kinderen met een gehoorbeperking met het blote oor van elkaar onderscheiden? Met een tweede, aanvullende onderzoeksvraag proberen we het antwoord op de eerste vraag nog wat te verfijnen: in hoeverre horen luisteraars een verschil tussen kinderen met een CI en kinderen met een akoestisch hoorapparaat?

\section{Focus 2: Ervaring van de luisteraars}

Luisteraars stemmen hun oor automatisch af op (de spraak van) de spreker. Dit fenomeen staat bekend als perceptual learning. Wie bijvoorbeeld geregeld doven hoort praten, verstaat deze groep vlotter dan iemand die zelden of nooit met doven in contact komt (McGarr, 1983). En een logopedist die geregeld kinderspraak hoort, detecteert meer fonetische details in die spraak dan een onervaren luisteraar (Munson, Johnson, \& Edwards, 2012). Precies omdat de perceptie van luisteraars sterk beïnvloed kan zijn door hun ervaring met een bepaald type spraak, integreren we deze factor als extra variabele in onze studie: we vergelijken de oordelen van logopedisten-audiologen, onderwijzers en onervaren luisteraars. Kunnen ze de verschillende groepen kinderen even goed van elkaar onderscheiden?

\section{Focus 3: Comparatieve aanpak}

Als aan luisteraars gevraagd wordt om de kwaliteit van spraak te evalueren, wordt vaak gebruik gemaakt van een schaal. Dat gebeurt bijvoorbeeld ook courant in studies naar de verstaanbaarheid van kinderen met een gehoorbeperking (Fang et al., 2014; Van Lierde, Vinck, Baudonck, De Vel, \& Dhooge, 2005). Schalen hebben voor- en nadelen. Een score aanduiden op een schaal kost weinig tijd. Bovendien kunnen luisteraars alle aspecten meenemen in hun oordeel die ze zelf relevant vinden. Anderzijds maakt dat het gebruik van een schaal en de interpretatie van de scores natuurlijk per definitie ook subjectief, wat o.a. kan leiden tot lage betrouwbaarheidsscores. Om de consistentie van de schaalbeoordeling te verhogen, kan de onderzoeker luisteraars inschakelen die het gewend zijn om spraak te beoordelen, bijvoorbeeld logopedisten (Chin \& Kuhns, 2014; Miller, 2013).

Daarmee komen we bij een ander fundamenteel probleem bij beoordelingstaken: menselijke oordelen zijn zelden consistent. Als beoordelaars verschillende keren hetzelfde item beoordelen, krijgt het niet altijd precies dezelfde score (Thurstone, 1927). Bovendien zijn menselijke oordelen ook niet absoluut: een 
beoordelaar gebruikt - bewust of onbewust - altijd een ijkpunt. Oftewel: All judgments are comparisons of one thing with another (Laming, 2004, p.9).

Een mogelijke oplossing voor deze methodologische dilemma's is paarsgewijze vergelijking. Om de beoordelaars een referentiepunt te bieden, kan de onderzoeker vragen om steeds twee items te vergelijken. De beoordelaars gaan dan na welke van twee stimuli een bepaalde eigenschap in hogere mate bezit (Thurstone, 1927; Bramley, 2007). Door de items paarsgewijs te vergelijken - waarbij dezelfde stimulus diverse malen terugkomt, steeds in combinatie met een andere stimulus - komt uiteindelijk een rangorde tot stand. Voordelen van deze benadering zijn de grote eenvoud en de betrouwbaarheid. De gebruiker kan een holistisch oordeel vellen over de stimuli (en hoeft dus bijvoorbeeld niet te wennen aan een schaal), en de oordelen van de luisteraars zijn consistenter. Omdat deze comparatieve benadering ons ook erg geschikt lijkt om spraakkwaliteit te beoordelen, doen we in deze bijdrage een beroep op D-PAC, een recent ontwikkelde tool voor paarsgewijze vergelijking (Lesterhuis et al., 2015; Lesterhuis, Verhavert, Coertjens, Donche, \& De Maeyer, 2017). Tot nu toe werd D-PAC vooral gebruikt voor de evaluatie van schrijfproducten in een onderwijscontext. In deze bijdrage zetten we deze tool voor het eerst in bij een onderzoek naar de spraak(kwaliteit) van kinderen met een gehoorbeperking.

\section{Methode}

\subsection{Stimuli}

De stimuli werden geselecteerd uit bestaande opnamen van een imitatietaak, gemaakt door Hide (2013). De imitatietaak bestond uit nonsenszinnen van het type "Ik heb X gezegd", waarbij X staat voor lala, lolo of lele. De steekproef bestond uit 21 kinderen: zeven met een CI, zeven met een akoestisch hoorapparaat en zeven met een normaal gehoor. Van elk kind werden at random zes uitingen geselecteerd, twee voor elke klinker ( $2 x$ “ik heb lolo gezegd", $2 x$ “ik heb lala gezegd", $2 \mathrm{x}$ "ik heb lele gezegd"). In totaal werkten we dus met 126 uitingen.

Op het moment van de opnamen waren de kinderen met een gehoorbeperking gemiddeld 7 jaar en 9 maanden oud $(S D=12 \mathrm{~m})$. Hun gehoordrempel zonder hoorhulpmiddel en de oorzaak van hun gehoorbeperking varieerden, maar hun gecorrigeerde gehoorverlies (d.w.z. het restgehoorverlies mét werkend akoestisch hoorapparaat of CI) was vergelijkbaar. De kinderen met een akoestisch hoorapparaat hadden oorspronkelijk een gehoorverlies van gemiddeld $66 \mathrm{dBHL}(S D=15$ $\mathrm{dBHL}$ ). Op het moment van de opname (mét werkend akoestisch hoorapparaat) bedroeg hun gehoorverlies gemiddeld nog $33 \mathrm{dBHL}(S D=7 \mathrm{dBHL})$. Hun rest- 
gehoorverlies was grosso modo vergelijkbaar met dat van de CI-kinderen, dat $29 \mathrm{dBHL}(S D=7 \mathrm{dBHL}$ ) bedroeg (Wilcoxon rangsomtoets: $z=0,91 ; p=0,37$ ). De gemiddelde implantatieleeftijd bij de CI-kinderen bedroeg 12 maanden. Zes van hen waren bilateraal geïmplanteerd. De kinderen met een akoestisch hoorapparaat droegen hun toestel gemiddeld vanaf de leeftijd van 11 maanden. Geen van de kinderen had bijkomende beperkingen. De kinderen hadden een basiskennis van gebarentaal, maar gebruikten doorgaans enkel gesproken Nederlands. De zeven normaalhorende kinderen waren klasgenoten van de CI-kinderen. Qua sekse, leeftijd en regionale achtergrond werden ze zo goed mogelijk gematcht met hun slechthorende leeftijdsgenoten. Voor meer details over onze steekproef verwijzen we naar Boonen, Kloots, Verhoeven \& Gillis (2019).

\subsection{Luisteraars}

Aan ons experiment werkten 60 luisteraars mee, stuk voor stuk moedertaalsprekers van het Nederlands. Hun regionale achtergrond was een constante factor: allemaal zijn ze afkomstig uit Belgisch-Limburg. Wat wel verschilde, was de mate waarin ze geregeld contact hebben met spraak van (o.a. slechthorende) kinderen. Het luisterpanel bestond namelijk uit 20 logopedisten met een specialisatie audiologie (gemiddelde leeftijd: 36 jaar; gemiddeld 12 jaar werkervaring), 20 onderwijzers (gemiddelde leeftijd: 40 jaar; gemiddeld 17 jaar werkervaring) en 20 onervaren luisteraars, d.w.z. luisteraars die geen specifieke ervaring hebben met de spraak van (slechthorende) kinderen (gemiddelde leeftijd: 41 jaar).

\subsection{Luistertaak}

De luisteraars beoordeelden de stimuli niet een voor een, maar per paar. Voor elk duo beantwoordden ze de vraag: "Welk kind klinkt het beste?". De instructie werd bewust heel algemeen geformuleerd. De luisteraars wisten vooraf dat ze spraak van kinderen met en zonder gehoorbeperking te horen zouden krijgen, maar kregen geen informatie over spraakkenmerken van kinderen met een gehoorbeperking. We wilden de aandacht c.q. de perceptie van de luisteraars namelijk niet in de richting van bepaalde stereotypes sturen. Ook wilden we de indruk vermijden dat bepaalde sprekers "goed" en andere "slecht" zouden spreken. Bij de beoordeling van de stimuli konden de luisteraars dus rekening houden met elk mogelijk facet dat hen relevant leek. Er werd gevraagd om regionale variatie en verschillen in opnamekwaliteit of volume te negeren - al valt natuurlijk moeilijk te achterhalen in hoeverre de luisteraars zich daaraan gehouden hebben.

De luistertaak werd gepresenteerd en verwerkt via de tool D-PAC (Digital Platform for the Assessment of Competence). Om de stimuli te rangschikken, 
maakt D-PAC gebruik van het Bradley-Terry-Luce-model (kortweg “BTL”), een statistisch model dat prestaties ordent van laag naar hoog op de relevante dimensie (Lesterhuis et al., 2017). Het computerprogramma vormt zich een beeld van de kwaliteit van een stimulus op basis van een $\mathrm{x}$-tal vergelijkingen door menselijke luisteraars, en kan vanaf dan zelf inschatten waar een bepaalde prestatie uiteindelijk terecht zal komen op de schaal. Webgebaseerde toepassingen zoals D-PAC maken het mogelijk om het BTL-model toe te passen op grote datasets (Pollitt, 2012). In ons geval berekent het model voor elke kinderuiting waar ze terecht zou komen op de schaal die varieert van "het minst goed klinkend" naar "het best klinkend”. Deze schatting levert uiteindelijk een rangorde met scores op, uitgedrukt in logits.

De statistische modellen achter een paarsgewijze comparatieve aanpak zijn erg robuust (Whitehouse \& Pollitt, 2012). Deelnemers hoeven dus niet elke mogelijke vergelijking te maken, en niet elk mogelijk paar hoeft vergeleken te worden om tot een betrouwbare rangorde te komen. Concreet moet elke stimulus tussen de 10 en de 20 keer beoordeeld worden (Bramley, 2015). De stimuli uit deze bijdrage werden door elke luisteraarsgroep (logopedisten-audiologen, onderwijzers, onervaren luisteraars) 20 keer beoordeeld, waarbij elke luisteraar in de praktijk 65 vergelijkingen maakte. Of de uiteindelijke rangorde - voor de drie luisteraarsgroepen tezamen - betrouwbaar was, werd onderzocht aan de hand van de Scale Separation Reliability measure (SSR). De SSR-score van ons experiment bedroeg gemiddeld .87, wat de kans klein maakt dat de rangorde beïnvloed is door meetfouten (Andrich, 1982).

\subsection{Dataverwerking}

Er werd een multilevelanalyse uitgevoerd met de opensourcesoftware R (R Core Team, 2016). Een multilevelanalyse is de geschikte analysetechniek voor hiërarchisch gestructureerde data en werkt met vaste effecten (fixed effects) en willekeurige effecten (random effects). Bij vaste effecten ligt vooraf vast welke waarden (levels) ze kunnen aannemen (bijvoorbeeld de hoorstatus van de kinderen). Bovendien zijn ze "herbruikbaar" (repeatable), wat concreet betekent dat ze bij replicatie van het experiment behouden blijven (met precies dezelfde waarden). Willekeurige effecten veranderen daarentegen wel bij replicatie, omdat ze at random geselecteerd zijn uit een ruimere populatie (bijvoorbeeld proefpersonen, spraakuitingen) (Baayen, 2008).

Bij ons experiment zijn de vaste effecten de hoorstatus van de kinderen (CI, akoestisch hoorapparaat, normaalhorend), de gebruiksduur van het hoorhulpmiddel (d.w.z. hoe lang draagt een kind zijn/haar CI of akoestisch hoorapparaat?) en het type luisteraars (logopedisten-audiologen, onderwijzers, onervaren luis- 
teraars). De willekeurige effecten zijn de individuele kinderen, de afzonderlijke uitingen en - bij het model gepresenteerd in 3.2 - de individuele luisteraars. De uiteindelijke totstandkoming van een multilevelmodel is een iteratief proces. De effecten worden een voor een toegevoegd. Elke keer dat er een effect bijkomt, wordt gekeken hoe het model erop reageert via een ANOVA-analyse. Alleen als een variabele het model significant verbetert, blijft hij behouden. In deze bijdrage wordt gefocust op de resultaten van de best fitting models.

We onderzoeken twee afhankelijke variabelen in twee afzonderlijke analyses waarin dezelfde vaste en willekeurige effecten getest worden. De eerste analyse focust op de plaats in de rangorde. Het D-PAC-experiment leverde een rangorde op, waarbij we de 126 stimuli in principe op twee manieren konden weergeven: op een ordinale schaal als een waarde van 1 tot 126, maar ook op een continue schaal in logits. Voor de statistische analyse in deze bijdrage nemen we de waarden uitgedrukt in logits als uitgangspunt. We gaan er namelijk van uit dat de afstand tussen twee stimuli in de rangorde variabel is, terwijl een ordinale schaal suggereert dat de afstand tussen de stimuli constant is. In de tweede analyse focussen we op de stimuli die bij de paarsgewijze beoordeling als de beste gerangschikt werden. In dit geval hebben we te maken met een binomiale variabele: een stimulus klinkt ofwel beter, ofwel slechter dan een andere.

\subsection{Hypothesen}

In deze paragraaf formuleren we enkele verwachtingen. Achtereenvolgens focussen we daarbij op de globale rangorde van de 126 uitingen en de analyse van de paarsgewijze vergelijkingen volgens hoorstatus. Ten slotte kijken we of ook vertrouwdheid met het type spraak een rol zou kunnen spelen.

\section{Perspectief 1: Globale rangorde van de 126 uitingen}

Allereerst willen we een beeld krijgen van de globale rangorde. Die geeft een algemene indruk van de spraakkwaliteit van de kinderen. Oftewel: waar vinden we de 126 uitingen uit ons experiment uiteindelijk terug? Als de luisteraars daadwerkelijk een verschil horen tussen normaal- en slechthorende kinderen, verwachten we dat de twee groepen duidelijk van elkaar gescheiden zullen zijn op de schaal. Hun uitingen zullen dan waarschijnlijk elk aan een (ander) uiteinde te vinden zijn.

Bekijken we binnen de slechthorende groep de kinderen met een akoestisch hoorapparaat en de CI-gebruikers afzonderlijk, dan verwachten we dat vooral zal doorwegen hoelang ze hun akoestisch hoorapparaat of implantaat al gebruiken (length of device use). Met name voor kinderen met een CI is immers al herhaaldelijk gebleken dat hun spraak verbetert naarmate ze hun CI langer dragen (Ertmer, 2007; Fang et al., 2014; Flipsen \& Colvard, 2006; Gillis, 2017). 
Perspectief 2: Analyse van de afzonderlijke paarsgewijze vergelijkingen volgens hoorstatus

In ons experiment worden steeds twee uitingen met elkaar vergeleken. Die twee uitingen kunnen afkomstig zijn van kinderen met een verschillende hoorstatus (bijvoorbeeld een normaalhorend kind en een kind met een CI), maar ook van kinderen met dezelfde hoorstatus (bijvoorbeeld twee kinderen met een akoestisch hoorapparaat). Als een van beide kinderen normaalhorend is, verwachten we dat zijn/haar uiting als beste geselecteerd zal worden. Voor vergelijkingen van een kind met een akoestisch hoorapparaat en een kind met een CI valt moeilijk te voorspellen welke uiting als beste beoordeeld zal worden. Het is bekend dat de spraakproductie van deze twee groepen kan verschillen, maar die verschillen wijzen niet altijd in dezelfde richting. Zo klinken de orale klanken van kinderen met een CI minder nasaal dan die van kinderen met een akoestisch hoorapparaat en een gehoorverlies groter dan $70 \mathrm{dBHL}$ (Baudonck et al., 2015), maar tegelijk produceren ze wel centralere klinkers (Verhoeven et al., 2016).

\section{Extra aandachtspunt: Ervaring van de luisteraars}

Een extra factor die we willen meenemen in ons onderzoek, is de mate waarin de luisteraars vertrouwd zijn met kinderspraak. Enerzijds kan geargumenteerd worden dat een luisteraar helemaal geen ervaring hoeft te hebben met een bepaald type spraak om te kunnen bepalen welke uiting het beste klinkt. Maar als deze factor wel iets uitmaakt, vermoeden we dat luisteraars die vertrouwd zijn met kinderspraak (onderwijzers, logopedisten-audiologen) een scherper onderscheid zullen (kunnen) maken tussen normaal- en slechthorende kinderen dan de onervaren luisteraars. Van de logopedisten-audiologen verwachten we dan dat ze ook een onderscheid horen tussen kinderen met een akoestisch hoorapparaat en kinderen met een CI.

\section{Resultaten}

Ons luisterpanel telde 60 deelnemers (zie 2.2). Hieronder presenteren we de resultaten van 56 luisteraars. Een misfit-analyse liet namelijk zien dat vier luisteraars afwijkend antwoordden ( $>2 \mathrm{SD}$ ). (Hoe D-PAC het begrip "misfit" definieert, is te vinden bij Lesterhuis et al., 2017,pp.127-128.) Concreet ging het om een logopedist-audioloog, een onderwijzer en twee onervaren luisteraars. Hun antwoorden worden hier buiten beschouwing gelaten. 


\subsection{Globale rangorde van de 126 uitingen}

Eerst vergelijken we de positie van normaalhorende en de slechthorende kinderen in het algemeen, d.w.z. zonder een onderscheid te maken tussen kinderen met een akoestisch hoorapparaat en kinderen met een CI. De resultaten van het beste model zijn te vinden in Tabel 1 . De geschatte plaats op de schaal is een numerieke waarde. Omdat we er rekening mee wilden houden dat de afstand tussen twee stimuli in de rangorde variabel is, wordt de positie van de stimuli in Figuur 1 uitgedrukt in logits (zie 2.4). Belangrijkste vaststelling: normaalhorende kinderen en kinderen met een gehoorbeperking nemen duidelijk een verschillende positie in op de schaal. De normaalhorende kinderen klonken volgens de luisteraars significant beter dan hun leeftijdsgenoten met een gehoorbeperking $(p<0,0001)$.

Tabel 1. Effect van hoorstatus "normaalhorend" $(\mathrm{NH})$ vs. "gehoorbeperking" $(\mathrm{HI})$ op de rangorde (met fixed effect = hoorstatus; random effects = de individuele kinderen, de individuele uitingen; intercept $=$ normaalhorende kinderen)

\begin{tabular}{lcccc}
\hline & Schatting & Standaardfout & $t$-waarde & $p$ \\
\hline Intercept & 1,5655 & 0,4659 & 3,3603 & $<0,001$ \\
Hoorstatus HI & $-2,3988$ & 0,5651 & $-4,2452$ & $<0,0001$ \\
\hline
\end{tabular}

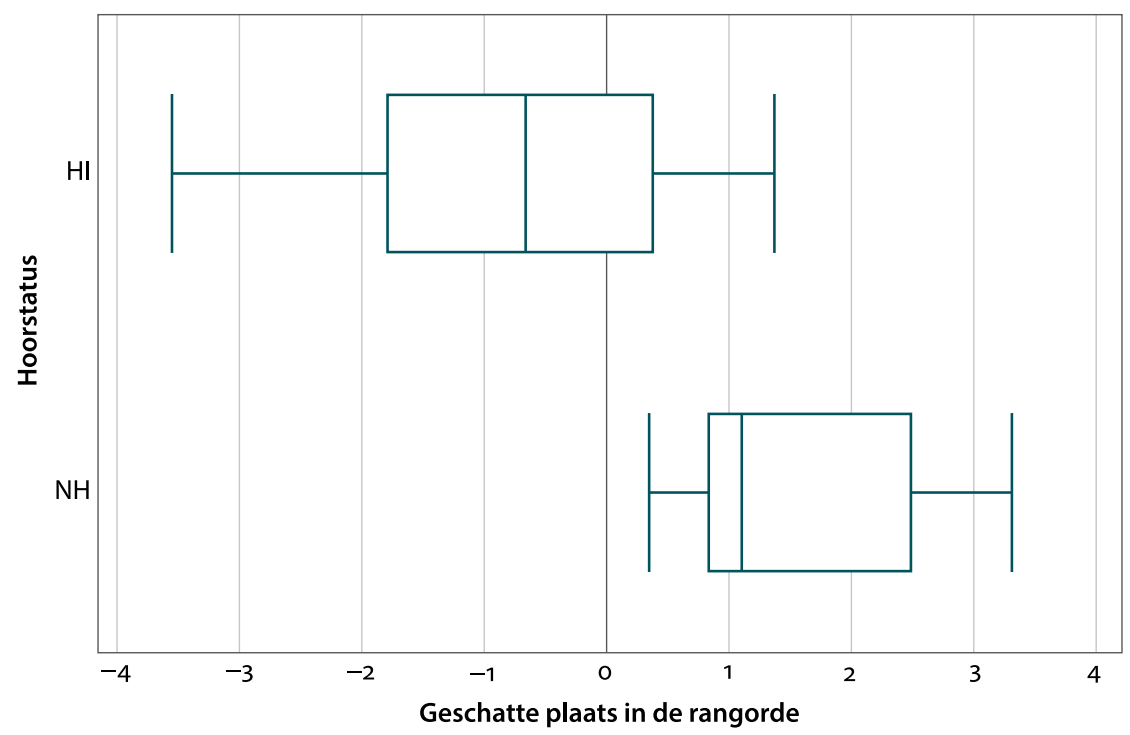

Figuur 1. Geschatte plaats in de rangorde voor normaalhorende $(\mathrm{NH})$ en kinderen met een gehoorbeperking (HI) (uitgedrukt in logits) 
Vervolgens onderzoeken we of luisteraars binnen de groep met een gehoorbeperking een onderscheid horen tussen kinderen met een akoestisch hoorapparaat en kinderen met een CI. Tabel 2 laat zien dat de geschatte plaats in de rangorde van kinderen met een CI en kinderen met een akoestisch hoorapparaat significant verschilt $(p<0,05)$. De spraakkwaliteit van kinderen met een CI wordt duidelijk hoger ingeschat. Ook hoelang de kinderen al over hun hoorapparaat of CI beschikken, is relevant. Naarmate kinderen hun hoorhulpmiddel langer gebruiken, komen ze significant hoger in de rangorde terecht. Deze tendens is echter beduidend sterker bij de kinderen met een CI. Bij de kinderen met een akoestisch hoorapparaat blijft de plaats in de rangorde nagenoeg constant (Figuur 2).

Tabel 2. Het verschil tussen kinderen met een akoestisch hoorapparaat (HA) en kinderen met een $\mathrm{CI}$ in de rangorde (met als fixed effects = hoorstatus, in interactie met de duur van de periode dat de kinderen het hoorhulpmiddel gebruiken; random effects = de individuele kinderen, de individuele uitingen; intercept $=$ kinderen met CI)

\begin{tabular}{lcccc}
\hline & Schatting & Standaardfout & $t$-waarde & $p$ \\
\hline Intercept & $-0,0979$ & 0,3654 & $-0,2678$ & $>0,05$ \\
Hoorstatus HA & $-1,1733$ & 0,4950 & $-2,3706$ & $<0,05$ \\
Gebruiksduur & 0,0813 & 0,0223 & 3,6478 & $<0,0005$ \\
$\begin{array}{l}\text { Interactie van hoorstatus HA en } \\
\text { gebruiksduur }\end{array}$ & $-0,0787$ & 0,0309 & $-2,5485$ & $<0,05$ \\
\hline
\end{tabular}

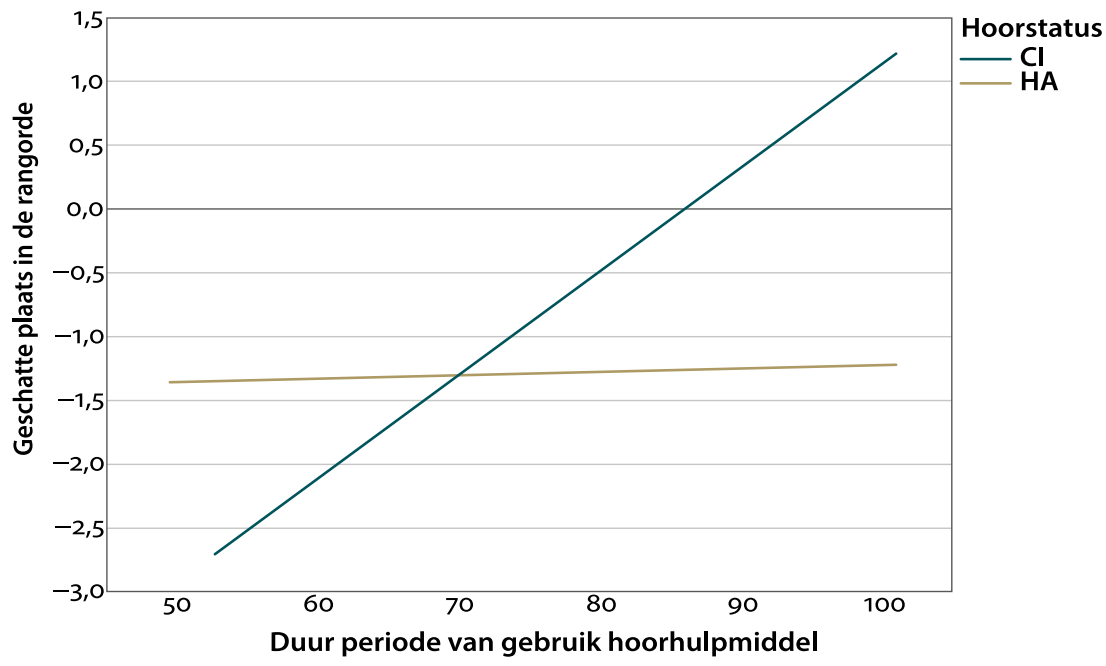

Figuur 2. Geschatte plaats in de rangorde voor kinderen met een akoestisch hoorapparaat en een CI, rekening houdend met de duur van de periode dat de kinderen hun hoorapparaat of CI gebruiken 
De factor luisteraarsgroep als vast effect toevoegen aan het model leverde geen beter resultaat op. Met andere woorden: de rangschikkingen van de drie luisteraarsgroepen zijn niet significant verschillend. Daarom werd deze variabele bij de analyse uiteindelijk buiten beschouwing gelaten.

\subsection{Analyse van de afzonderlijke paarsgewijze vergelijkingen volgens hoorstatus}

Tot nu toe onderzochten we de globale rangorde van de 126 uitingen (zie 3.1). In de praktijk werden echter steeds twee willekeurige uitingen met elkaar vergeleken. De luisteraars maakten in totaal 3900 vergelijkingen, waarvan er uiteindelijk 3640 geanalyseerd werden ( $=56$ luisteraars x 65 vergelijkingen). Met andere woorden: we buigen ons hier opnieuw over de vraag "Welk kind klinkt het best?", maar dit keer vanuit het perspectief van de paarsgewijze vergelijkingen.

In principe zijn er zes combinaties mogelijk (Tabel 3). In deze paragraaf analyseren we alleen de paren waarbij kinderen met een verschillende hoorstatus vergeleken worden (= type 1 in Tabel 3).

Tabel 3. Combinatie van uitingen met verschillende (type 1) en dezelfde (type 2)

hoorstatus bij de paarsgewijze vergelijking

Type 1 - geanalyseerd (2461 vergelijkingen)

Type 2 - niet-geanalyseerd (1179

vergelijkingen)

normaalhorend kind - kind met akoestisch

twee normaalhorende kinderen

hoorapparaat

normaalhorend kind - kind met CI

twee kinderen met akoestisch hoorapparaat

kind met akoestisch hoorapparaat - kind met CI

twee kinderen met $\mathrm{CI}$

Figuur 3 laat zien wat de kans (likelihood) is dat een uiting als beste geselecteerd wordt in een vergelijking van twee uitingen met een verschillende hoorstatus. De achterliggende statistische modellen voor elk type vergelijking zijn te vinden in de Bijlage. Als luisteraars een normaalhorend kind en een kind met een CI horen, vinden ze meestal dat het normaalhorende kind het beste klinkt ( $83 \%$ vs. $17 \%$ ). Bij vergelijkingen met een normaalhorend kind en een kind met een akoestisch hoorapparaat is het contrast nog groter: ook daar scoren de normaalhorende kinderen het beste ( $92 \%$ vs. $8 \%$ ). Bij de vergelijkingen van kinderen met een CI en kinderen met een akoestisch hoorapparaat behalen de kinderen met een CI de hoogste score. In $67 \%$ van de gevallen oordelen de luisteraars dat het kind met CI het beste klinkt, in 33\% van de gevallen appreciëren de luisteraars de uiting van het kind met het akoestisch hoorapparaat het meest. 


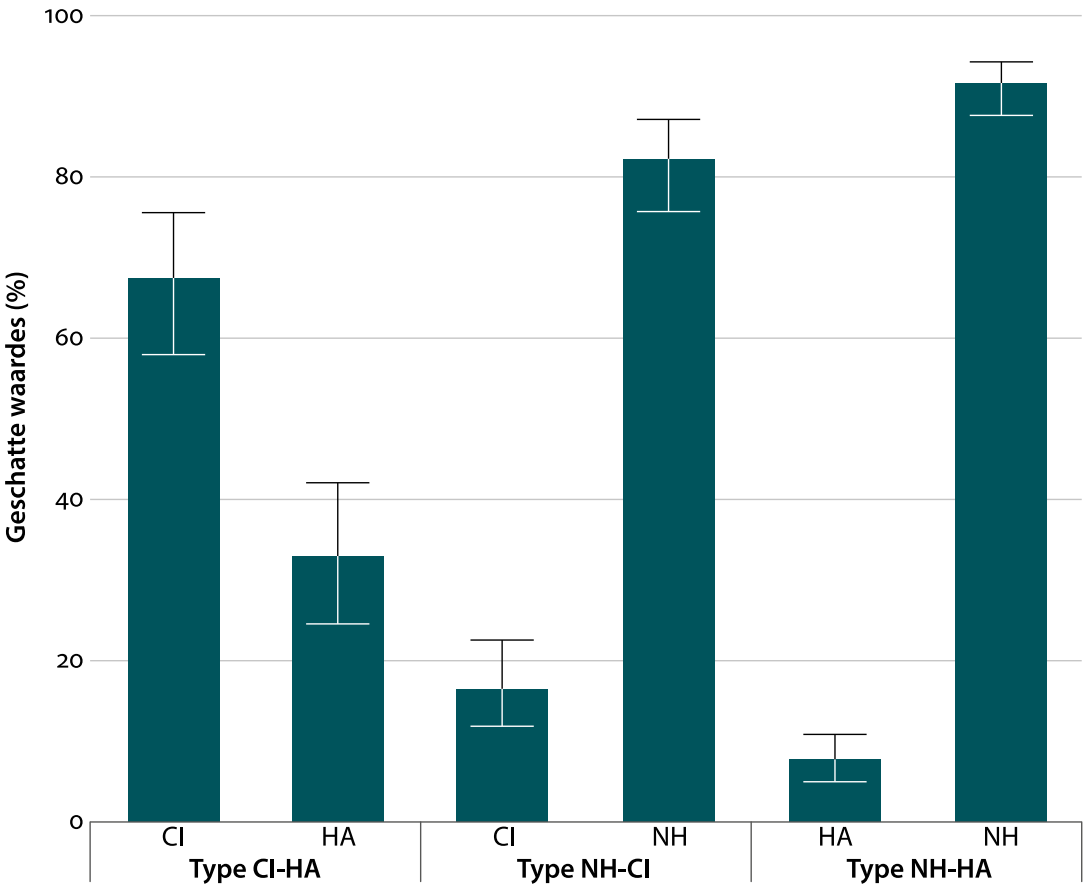

Figuur 3. Kans (likelihood) dat een uiting als beste geselecteerd wordt van twee uitingen met verschillende hoorstatus (uitgedrukt in \% met aanduiding van de standaardfout), met $\mathrm{NH}=$ normaalhorend, $\mathrm{HA}=$ akoestisch hoorapparaat en $\mathrm{CI}=$ cochleair implantaat

Ook bij deze analyse leverde de toevoeging van de factor luisteraarsgroep aan het statistische model geen beter resultaat op. Met andere woorden: de oordelen van de drie luisteraarsgroepen zijn niet significant verschillend. Daarom wordt deze variabele ook hier niet verder geanalyseerd.

\section{Discussie}

\subsection{Duiding van de resultaten}

In de vorige paragraaf presenteerden we de resultaten van ons experiment in twee stappen. Eerst maakten we een globale analyse van de 126 geselecteerde uitingen (cf. 3.1). Vervolgens focusten we op de afzonderlijke paarsgewijze vergelijkingen volgens hoorstatus (cf. 3.2). In deze paragraaf houden we dezelfde volgorde aan.

Een eerste vaststelling: de normaalhorende kinderen klinken volgens onze luisteraars gemiddeld genomen beter dan kinderen met een akoestisch hoorapparaat en kinderen met een CI. Met andere woorden: zelfs wanneer een kind 
al geruime tijd een hoorhulpmiddel gebruikt, blijven luisteraars "iets" aan de spraak horen. In de vakliteratuur is al vaker gewezen op verschillen in spraakproductie tussen normaalhorende kinderen en kinderen met een gehoorbeperking (zie bijvoorbeeld Baudonck et al., 2015; Vanormelingen et al., 2016; Verhoeven et al., 2016; Gillis, 2017). Het lijkt er dus op dat luisteraars deze specifieke kenmerken ook (blijven) horen. Het zou interessant zijn om na te gaan welke kenmerken daarbij precies de doorslag geven, ook voor de spraaktherapeuten die kinderen met een CI of akoestisch hoorapparaat begeleiden. Zo'n verdiepend onderzoek opzetten is echter geen sinecure. Uit een verkennende rondvraag bij onze huidige luisteraars naar de doorslaggevende kenmerken kwamen namelijk de meest uiteenlopende antwoorden naar voren.

Een tweede vaststelling: hoelang kinderen hun hoorhulpmiddel al gebruiken, heeft een veel grotere (positieve) invloed bij kinderen met een CI dan bij kinderen met een akoestisch hoorapparaat. Oftewel: hoe langer kinderen al een CI dragen, hoe beter ze volgens de luisteraars klinken. Bij de kinderen met een akoestisch hoorapparaat lijkt het verschil in gebruiksduur daarentegen weinig uit te maken. Een mogelijke verklaring zou kunnen schuilen in het feit dat een CI en een akoestisch hoorapparaat twee fundamenteel verschillende toestellen zijn. Een CI zorgt ervoor dat kinderen een frequentieresolutie kunnen waarnemen die voorheen geheel ontbrak. Naarmate hun hersenen meer en meer gewend raken aan deze resolutie, begint hun spraak beter en beter te klinken (Kral \& Sharma, 2012). Bij een akoestisch hoorapparaat liggen de zaken anders. Hier verhoogt de gehoordrempel omdat de frequentieresolutie nu beter "doorkomt". Met andere woorden: het geluid wordt door het akoestisch hoorapparaat versterkt, maar de hersenen hoeven niet te wennen aan een nieuw gegeven. Een en ander zou meteen ook kunnen verklaren waarom in de vakliteratuur rond cochleaire implantaten geregeld gewezen wordt op de invloed van length of device use (zie bijvoorbeeld Ertmer, 2007; Fang et al., 2014; Flipsen \& Colvard, 2006; Gillis, 2017), maar in de vakliteratuur rond spraak van kinderen met een akoestisch hoorapparaat veel minder.

De analyse van de afzonderlijke paarsgewijze vergelijkingen volgens hoorstatus liet zien dat normaalhorende kinderen volgens de luisteraars beter klinken dan kinderen met een CI en kinderen met een akoestisch hoorapparaat. Verder viel vooral het verschil op tussen kinderen met een CI en kinderen met een akoestisch hoorapparaat (Figuur 3). De kinderen met een CI klinken volgens onze luisteraars gemiddeld beter dan hun leeftijdsgenoten met een akoestisch hoorapparaat. De vakliteratuur biedt hiervoor slechts een gedeeltelijke verklaring. In diverse studies leek de spraak van de CI-gebruikers sterker op de spraak van normaalhorenden dan de spraak van sprekers met een akoestisch hoorapparaat (bijvoorbeeld Van Lierde et al., 2005; Baudonck et al., 2015) - wat de hogere scores van de CIgroep in Figuur 3 kan verklaren. Maar er zijn ook tegenvoorbeelden: uit de studie 
van Verhoeven et al. (2016) kwam bijvoorbeeld naar voren dat de klinkers van CIgebruikers een centralere plaats innemen in de klinkerruimte dan die van sprekers met een akoestisch hoorapparaat. Ook wat de paarsgewijze vergelijkingen volgens hoorstatus betreft concluderen we dus dat er verder onderzoek nodig is naar de doorslaggevende factoren bij de beoordeling van spraakkwaliteit. Hierbij zou bijvoorbeeld ook gekeken kunnen worden naar het effect van het aanbieden van gebarentaal of naar de hoeveelheid taalondersteuning (zoals logopedie) die beide groepen krijgen na activatie van hun hoorhulpmiddel.

\subsection{Beperkingen en perspectieven}

Bij de samenstelling van onze steekproef hanteerden we een aantal strikte criteria. Zo hielden we rekening met chronologische leeftijd, gehoordrempel en leeftijd op het moment van implantatie resp. op het moment dat de kinderen hun akoestisch hoorapparaat kregen. Bovendien controleerden we of de deelnemende kinderen geen fysieke of mentale beperkingen hadden. Geografisch gezien beperkt onze steekproef zich tot kinderen uit Vlaanderen. Deze principiële keuzes leverden een vrij homogene, maar wel kleine steekproef op. Het zou interessant zijn om het experiment in de toekomst te kunnen herhalen met een uitgebreidere steekproef. Ook de variatie in de spraak van de individuele kinderen zou nog verder onderzocht kunnen worden, zowel over de verschillende groepen heen als binnen een groep kinderen met dezelfde hoorstatus.

Mocht het experiment herhaald worden met een grotere steekproef, dan verdient de factor gehoordrempel daarbij bijzondere aandacht. Om onze steekproef zo homogeen mogelijk te maken, matchten we de kinderen met een gehoorbeperking (o.a.) op gehoordrempel. Mét werkend hoorapparaat of CI hebben ze allemaal nog een restgehoorverlies van ongeveer $30 \mathrm{dBHL}$ (cf. 2.1). Voor kinderen met een $\mathrm{CI}$ is een restgehoorverlies van $30 \mathrm{dBHL}$ een gebruikelijke score. Bij kinderen met een akoestisch hoorapparaat is een restgehoorverlies van $30 \mathrm{dBHL}$ echter vrij hoog. Het gaat hier om kinderen bij wie het akoestisch hoorapparaat het gehoorverlies blijkbaar niet optimaal kan opvangen. Of nog concreter geformuleerd: er zijn heel wat kinderen met een hoorapparaat die beter horen dan degenen die wij selecteerden voor ons experiment. Mogelijk kan dat ook mee verklaren waarom we de luisteraars de uitingen van de kinderen met CI beter vonden klinken (Figuur 3). Kinderen met een akoestisch hoorapparaat die een kleiner restgehoorverlies hebben, halen mogelijk hogere scores.

Ook vanuit methodologisch oogpunt biedt ons experiment perspectieven voor toekomstig onderzoek. De tool D-PAC werd tot nu toe vooral gebruikt in een onderwijscontext. Onze studie toont echter aan dat D-PAC ook geschikt is voor de beoordeling van spraakfragmenten. Spraakkwaliteit beoordelen gebeurt 
meestal op een schaal, al dan niet door professionals (cf. Chin \& Kuhns, 2014; Schiavetti, 1992). Bij het gebruik van een schaal kunnen de verschillen tussen de luisteraars echter hoog oplopen (Miller, 2013). Een mogelijk alternatief bestaat erin om spraakkwaliteit holistisch te beoordelen (d.w.z. oordelen op basis van een algemene indruk), maar ook die benadering heeft nadelen, zeker voor luisteraars die weinig ervaring hebben met een bepaald type spraak (zie ook Lesterhuis et al., 2015). Zoals toegelicht in de inleiding hebben beoordelaars namelijk een ijkpunt nodig om zinvolle uitspraken te kunnen doen over uitingen. Een onervaren luisteraar mist bij de holistische benadering houvast. Bij de comparatieve aanpak met D-PAC - waarbij steeds twee uitingen vergeleken worden - is per definitie een ijkpunt voorhanden, waardoor deze tool een interessant en betrouwbaar alternatief biedt voor de traditionele benaderingen zoals schalen.

Een extra variabele in deze studie vormde de mate waarin de luisteraars ervaring hebben met kinderspraak. De uitingen werden beoordeeld door 20 logopedisten-audiologen, 20 onderwijzers en 20 onervaren luisteraars. De antwoorden van deze drie groepen bleken uiteindelijk niet significant van elkaar te verschillen. Met andere woorden: ongeacht het feit of luisteraars beroepshalve geregeld kinderspraak horen, vinden ze - globaal genomen - dat dezelfde uitingen het beste klinken. Deze bevinding biedt interessante methodologische perspectieven.

- Als de oordelen van onervaren luisteraars en professionals niet significant verschillen, valt te overwegen om in de toekomst vaker onervaren luisteraars in te schakelen bij comparatieve luisterexperimenten. Hierdoor zou het eenvoudiger worden om snel een uitgebreid luisterpanel samen te stellen. Om te kunnen bepalen of een uiting het beste klinkt, hebben luisteraars blijkbaar geen bijzondere kennis (zoals vaktermen) of vaardigheden (bijvoorbeeld fonetisch transcriberen) nodig. Het volstaat dat ze geconcentreerd naar de uitingen luisteren.

- Als de oordelen van onervaren luisteraars en professionals niet significant verschillen, valt ook te overwegen om in de toekomst ouders en andere opvoeders van kinderen met een gehoorbeperking nog veel meer als volwaardige partners te beschouwen bij de beoordeling van de spraakontwikkeling van hun kinderen. Opvolging door professionals blijft uiteraard cruciaal, maar er zou ook (explicieter) aan ouders en andere opvoeders gevraagd kunnen worden of de spraak van kinderen erop verbeterd is. De beoordeling door een professional is immers vaak een momentopname. Om deze piste verder uit te spitten, zou er een vergelijking kunnen worden gemaakt tussen de beoordelingen van ouders van kinderen met en zonder gehoorbeperking en, bijvoorbeeld, professionals. 
- Anderzijds: het feit dat de drie luisteraarsgroepen globaal genomen tot dezelfde bevindingen kwamen, betekent natuurlijk niet dat alle luisteraars de taak ook allemaal even eenvoudig vonden. Mogelijk vergde het luisterexperiment van de onervaren luisteraars wel meer concentratie en moeite dan van de onderwijzers en de logopedisten-audiologen. Hoe moeilijk de drie types van luisteraars de vergelijkingstaak vonden, zou een interessante piste zijn voor vervolgonderzoek.

Nog een laatste methodologische bedenking: de luisteraars kregen vooraf geen informatie over de specifieke kenmerken van spraak van kinderen met een akoestisch hoorapparaat of CI (cf. 2.3), maar ze waren zich er wel van bewust dat een deel van de spraak die ze hoorden afkomstig was van kinderen met een gehoorbeperking. Het zou interessant zijn om na te gaan in hoeverre deze (beperkte) voorkennis de oordelen van de luisteraars beïnvloed heeft.

\section{Conclusie}

In deze bijdrage presenteerden we de resultaten van een comparatief experiment waarbij een luisterpanel van 6o luisteraars zo'n 126 uitingen, afkomstig van normaal- en slechthorende kinderen, rangschikten volgens kwaliteit. De luisteraars kregen steeds twee uitingen te horen en gaven aan welk van beide kinderen volgens hen het beste klonk. De spraak van normaalhorende kinderen werd duidelijk als beter beschouwd dan de spraak van hun leeftijdsgenoten met een gehoorbeperking. Bij de spraak van de slechthorende kinderen genoot de spraak van kinderen met een CI de voorkeur. Die voorkeur werd nog sterker naarmate de kinderen hun CI langer droegen. Of luisteraars vertrouwd waren met kinderspraak, bleek geen doorslaggevende factor: logopedisten-audiologen en onderwijzers kwamen tot vergelijkbare bevindingen als luisteraars zonder specifieke ervaring met kinderspraak. Onze resultaten laten zien dat de comparatieve paarsgewijze beoordeling met een digitale tool als D-PAC een interessant alternatief vormt voor de traditionele schaalbeoordeling.

\section{Ondersteuning}

De eerste auteur is Aspirant van het Fonds voor Wetenschappelijk Onderzoek - Vlaanderen (FWO-1100316N). Haar onderzoeksproject werd goedgekeurd door de Ethische Commissie voor de Sociale en Humane Wetenschappen (SHW_15_37) van de Universiteit Antwerpen. 


\section{Dankwoord}

Deze onderzoeksresultaten werden gepresenteerd als full paper op de Anéla-conferentie van 1-2 juni 2018. We danken de aanwezigen - in het bijzonder Warda Nejjari - voor hun waardevolle feedback.

\section{Bibliografie}

Andrich, D. (1982). An index of person separation in latent trait theory, the traditional KR-20 index, and the Guttman scale response pattern. Education Research and Perspectives, 9(1), 95-104.

Baayen, R.H. (2008). Analyzing linguistic data. A practical introduction to statistics using $R$. Cambridge: Cambridge University Press. https://doi.org/10.1017/CBO9780511801686

Baudonck, N., Van Lierde, K., D’Haeseleer, E., \& Dhooge, I. (2015). Nasalance and nasality in children with cochlear implants and children with hearing aids. International Journal of Pediatric Otorhinolaryngology, 79(4), 541-545. https://doi.org/10.1016/j.ijporl.2015.01.025

Boonen, N., Kloots, H., Verhoeven, J., \& Gillis, S. (2019). Can listeners hear the difference between children with normal hearing and children with a hearing impairment? Clinical Linguistics \& Phonetics, 33(4), 316-333. https://doi.org/10.1080/02699206.2018.1513564

Bramley, T. (2007). Paired comparison methods. In P. Newton, J.-A. Baird, H. Goldstein, H. Patrick, \& P. Tymms (Eds.), Techniques for monitoring the comparability of examination standards (pp. 246-294). London: QCA.

Bramley, T. (2015). Investigating the reliability of Adaptive Comparative Judgment. Cambridge, UK: Cambridge Assessment Research Report.

Chin, S. B., \& Kuhns, M.J. (2014). Proximate factors associated with speech intelligibility in children with cochlear implants: A preliminary study. Clinical Linguistics \& Phonetics, 28(7-8), 532-542. https://doi.org/10.3109/02699206.2014.926997

Crystal, D. (2003). A dictionary of linguistics and phonetics. Oxford: Wiley-Blackwell.

Ertmer, D. J. (2007). Speech intelligibility in young cochlear implant recipients: Gains during year three. The Volta Review, 107(2), 85-99. https://doi.org/10.17955/tvr.107.2.585

Fang, H.-Y., Ko, H.-C., Wang, N.-M., Fang, T.-J., Chao, W.-C., Tsou, Y.-T., \& Wu, C.-M. (2014). Auditory performance and speech intelligibility of Mandarin-speaking children implanted before age 5. International Journal of Pediatric Otorhinolaryngology, 78(5), 799-803. https://doi.org/10.1016/j.jpporl.2014.02.014

Flipsen, P., \& Colvard, L. G. (2006). Intelligibility of conversational speech produced by children with cochlear implants. Journal of Communication Disorders, 39(2), 93-108. https://doi.org/10.1016/j.jcomdis.2005.11.001

Gillis, S. (2017). Speech and language in congenitally deaf children with a cochlear implant. In A. Bar-On, \& D. Ravid (Eds.), Handbook of communication disorders: Theoretical, empirical, and applied linguistic perspectives (pp. 763-790). Berlin: Mouton De Gruyter.

Hide, $\varnothing$. (2013). Acoustic features of speech by young cochlear implant users. A comparison with normal-hearing and hearing-aided age mates. Ongepubliceerd proefschrift, Universiteit Antwerpen. 
Kral, A., \& O’Donoghue, G. (2010). Profound deafness in childhood. The New England Journal of Medicine, 363(15), 1438-1450. https://doi.org/10.1056/NEJMrao911225

Kral, A., \& Sharma, A. (2012). Developmental neuroplasticity after cochlear implantation. Trends in Neurosciences, 35(2), 111-122. https://doi.org/10.1016/j.tins.2011.09.004

Laming, D. (2004). Human judgment: The eye of the beholder. Hongkong: Thomson Learning.

Lesterhuis, M., Donche, V., De Maeyer, S., Van Daal, T., Van Gasse, R., Coertjens, L., Verhavert, S., Mortier, A., Coenen, T., Vlerick, P., Vanhoof, J., \& Van Petegem, P. (2015). Competenties kwaliteitvol beoordelen: brengt een comparatieve aanpak soelaas? Tijdschrift voor hoger onderwijs, 33(2), 55-67.

Lesterhuis, M., Verhavert, S., Coertjens, L., Donche, V., \& De Maeyer, S. (2017). Comparative judgment as a promising alternative to score competences. In E. Cano, \& G. Ion (Eds.), Innovative practices for higher education assessment and measurement (pp. 119-138). Hershey: IGI Global. https://doi.org/10.4018/978-1-5225-0531-0.choo7

McGarr, N. (1983). The intelligibility of deaf speech to experienced and inexperienced listeners. Journal of Speech and Hearing Research, 26(3), 451-458. https://doi.org/10.1044/jshr.2603.451

Miller, N. (2013). Measuring up to speech intelligibility. International Journal of Language \& Communication Disorders, 48(6), 601-612. https://doi.org/10.1111/1460-6984.12061

Munson, B., Johnson, J.M., \& Edwards, J. (2012). The role of experience in the perception of phonetic detail in children's speech: A comparison between speech-language pathologists and clinically untrained listeners. American Journal of Speech-Language Pathology, 21(2), 124-139. https://doi.org/10.1044/1058-0360(2011/11-0009)

Nicholas, J.G., \& Geers, A.E. (2007). Will they catch up? The role of age at cochlear implantation in the spoken language development of children with severe to profound hearing loss. Journal of Speech, Language, and Hearing Research, 50(4), 1048-1062. https://doi.org/10.1044/1092-4388(2007/073)

Pollitt, A. (2012). Comparative judgement for assessment. International Journal of Technology and Design Education, 22(2), 157-170. https://doi.org/10.1007/s10798-011-9189-x

R Core Team. (2016). R: A language and environment for statistical computing. Vienne, Austria: $\mathrm{R}$ foundation for statistical computing. [http://www.R-project.org/]

Schiavetti, N. (1992). Scaling procedures for the measurement of speech intelligibility. In R.D. Kent (Ed.), Intelligibility in speech disorders: Theory, measurement and management (pp. 11-34). Amsterdam: John Benjamins Publishing Company. https://doi.org/10.1075/sspcl.1.02sch

Thurstone, L. (1927). A law of comparative judgment. Psychological Review, 34, 273-286. Herdrukt in Psychological Review, 1994, 101(2), 266-270. https://doi.org/10.1037/hoo70288

Van Lierde, K. M., Vinck, B. M., Baudonck, N., De Vel, E., \& Dhooge, I. (2005). Comparison of the overall intelligibility, articulation, resonance, and voice characteristics between children using cochlear implants and those using bilateral hearing aids: A pilot study. International Journal of Audiology, 44(8), 452-465.

https://doi.org/10.1080/14992020500189146

Vanormelingen, L., De Maeyer, S., \& Gillis, S. (2016). A comparison of maternal and child language in normally-hearing and hearing-impaired children with cochlear implants. Language, Interaction and Acquisition, 7(2), 145-179. https://doi.org/10.1075/lia.7.2.01van 
Verhoeven, J., Hide, Ø., De Maeyer, S., Gillis, S., \& Gillis, S. (2016). Hearing impairment and vowel production. A comparison between normally hearing, hearing-aided and cochlear implanted Dutch children. Journal of Communication Disorders, 59, 24-39. https://doi.org/10.1016/j.jcomdis.2015.10.007

Whitehouse, C., \& Pollitt, A. (2012). Using Adaptive Comparative Judgement to obtain a highly reliable rank order in summative assessment. Gedownload via https://cerp.aqa.org.uk/sites /default/files/pdf_upload/CERP_RP_CW_20062012_2.pdf [07.02.2019]. Manchester: Centre for Education Research and Policy.

\section{Bijlage}

Deze bijlage bevat het beste statistische model voor elk type van paarsgewijze vergelijking met twee verschillende hoorstatussen.

a. Vergelijking van normaalhorende kinderen en kinderen met CI

Tabel 4. Fixed effect-resultaten voor de kans (likelihood) dat een uiting als beste geselecteerd wordt in een vergelijking van het type normaalhorend - CI (met fixed effect = hoorstatus; random effect = individuele kinderen, individuele uitingen; intercept $=$ normaalhorende kinderen)

\begin{tabular}{lrcrc}
\hline & Intercept & Standaardfout & $z$-waarde & $p$ \\
\hline Intercept & 1,5224 & 0,3831 & 3,974 & $<0,0001$ \\
Hoorstatus CI & $-3,1406$ & 0,5460 & $-5,752$ & $<0,0001$ \\
\hline
\end{tabular}

b. Vergelijking van normaalhorende kinderen en kinderen met akoestisch hoorapparaat (HA)

Tabel 5. Fixed effect-resultaten voor de kans (likelihood) dat een uiting als beste geselecteerd wordt in een vergelijking van het type normaalhorend - akoestisch hoorapparaat (met fixed effect = hoorstatus; random effect $=$ individuele kinderen, individuele uitingen en individuele luisteraars; intercept $=$ normaalhorende kinderen)

\begin{tabular}{lrcrc}
\hline & Intercept & Standaardfout & $z$-waarde & $p$ \\
\hline Intercept & 2,3820 & 0,4155 & 5,7330 & $<0,0001$ \\
Hoorstatus HA & $-4,9065$ & 0,5284 & $-9,2860$ & $<0,0001$ \\
\hline
\end{tabular}


c. Vergelijking van kinderen met een akoestisch hoorapparaat (HA) en kinderen met CI

Tabel 6. Fixed effect-resultaten voor de kans (likelihood) dat een uiting als beste geselecteerd wordt in een vergelijking van het type cochleair implantaat - akoestisch hoorapparaat (met fixed effect = hoorstatus; random effect = individuele kinderen, individuele uitingen; intercept $=$ kinderen met CI)

\begin{tabular}{lcccc}
\hline & Intercept & Standaardfout & $z$-waarde & $p$ \\
\hline Intercept & 0,7218 & 0,4012 & 1,799 & 0,0720 \\
Hoorstatus HA & $-1,4435$ & 0,5480 & $-2,634$ & $<0,01$ \\
\hline
\end{tabular}

\section{Correspondentieadres}

Nathalie Boonen

University of Antwerp

Department of Linguistics - CLiPS

Prinsstraat 13

2000 Antwerp

Belgium

nathalie.boonen@uantwerpen.be

(D) https://orcid.org/oooo-0oo2-5345-1484

\section{Co-auteur informatie}

Hanne Kloots

University of Antwerp

Department of Linguistics - CLiPS

hanne.kloots@uantwerpen.be
Steven Gillis

University of Antwerp

Department of Linguistics - CLiPS

steven.gillis@uantwerpen.be

\section{Publicatiegeschiedenis}

Date received: 26 July 2018

Date accepted: 11 September 2019

Published online: 24 October 2019 